\title{
Fructose phosphotransferase system of Xanthomonas campestris pv. campestris : characterization of the fruB gene
}

\author{
Valérie de Crécy-Lagard, ${ }^{1}+$ Marie Binet ${ }^{2}$ and Antoine Danchin ${ }^{1}$
}

1 Unité de Régulation de l'Expression génétique, Institut Pasteur, 75724 Paris cedex 15, France

2 Unité des Entérobactéries, Institut Pasteur, 75724 Paris cedex 15, France
Author for correspondence: Antoine Danchin. Tel: +33145688442 . Fax: +33145688949. e-mail: adanchin@pasteur.fr
Keywords: Xanthomonas campestris, fructose transport, PTS, multiphosphoryl transfer protein, 1-phosphofructokinase

\section{INTRODUCTION}

The phytopathogenic Gram-negative bacterium Xanthomonas campestris pv. campestris has the property of secreting large quantities of an exopolysaccharide, xanthan gum (Jeanes et al., 1961), used in a variety of industrial and food applications (Sutherland \& Ellwood, 1979). The study of carbohydrate metabolism in this organism is of great interest, for the understanding of both xanthan gum biosynthesis and the mechanisms of plant colonization by the pathogen. We have previously shown that fructose is transported in this bacterium by a phosphoenolpyruvate-(PEP-)dependent phosphotransferase system (PTS) which, using PEP as the energy source, catalyses the transport and phosphorylation of fructose to yield intracellular fructose 1-phosphate (De

†Present address: Unité de Biochimie Microbienne, Institut Pasteur, 75724 Paris cedex 15, France.

Abbreviations: DTP, diphosphoryl transfer protein; MTP, multiphosphoryl transfer protein; PEP, phosphoenolpyruvate; 1-PFK, 1phosphofructokinase; PTS, phosphotransferase system.

The EMBL accession number for the sequence reported in this paper is Z37113 xamtp.
Crécy-Lagard et al., 1991b). Bacterial PTSs are complex, including membrane-bound-sugar specific components called Enzymes II. Enzymes II consist of three domains that can be either fused together or free: one integral membrane carbohydrate recognition component, EIIC, and two cytoplasmic components, EIIB and EIIA (Saier et al., 1988; Saier \& Reizer, 1992). The phosphoryl group is transferred from PEP to the EIIs by two general components, Enzyme I (EI) and HPr. The phosphate transfer cascade from PEP to the PTS sugar can be summarized as follows:

$$
\begin{aligned}
& \mathrm{PEP} \rightarrow \mathrm{EI} \sim \mathrm{P} \rightarrow \mathrm{HPr} \sim \mathrm{P} \rightarrow \mathrm{EIIA} \sim \mathrm{P} \rightarrow \mathrm{EIIB} \sim \mathrm{P} \stackrel{\mathrm{EIIC}}{\rightarrow} \\
& \text { sugar } \sim \mathrm{P}
\end{aligned}
$$

The $X$. campestris fru $A$ gene, encoding the fructosespecific permease (EIIB' ${ }^{\prime} C^{\mathrm{Fru}}$ ), and the fruK gene, encoding the 1-phosphofructokinase (1-PFK) which contributes to further metabolism of fructose, have been cloned and sequenced (De Crécy-Lagard et al., 1991a, b). The nucleotide sequence of complete fru operons has now been determined in three organisms: Eschericbia coli, Salmonella typbimurium (Prior \& Kornberg, 1988; Geerse et al., 1989; Orchard \& Kornberg, 1990; Reizer et al., 
1994b) and Rhodobacter capsulatus (Wu et al., 1990, 1991; Wu \& Saier, 1990). In enteric bacteria, the fru operon consists of the genes fruBK $A$; fruB encodes the diphosphoryl transfer protein (DTP) which combines the functions of an EIIA ${ }^{\text {Fru }}$ domain and an HPr-like protein. In $R$. capsulatus, the fru operon consists of the genes fruBK $A$; fruB encodes a protein named MTP (for multiphosphoryl transfer protein) which combines the EIIA $^{\text {Fru }}, \mathrm{HPr}$ and EI domains. In this paper, we establish the nucleotide sequence of the general PTS genes of $X$. campestris and discuss the organization of the fructose PTS genes in this organism.

\section{METHODS}

Bacterial strains, plasmids, media and growth conditions. The $X$. campestris strains used were the wild-type strain NRRL B1459 (Jeanes et al., 1961) and XC1504 (fru-2::Omegon-Km) (De Crécy-Lagard et al., 1991b). E. coli XL1-Blue [rec $A 1$ end $A 1$ gyr $A 96$ thi bsdR 17 supE44 relA1 $\lambda^{-}$(lac) $\left\{\mathrm{F}^{\prime}\right.$ pro $A B$ lac ${ }^{q} Z \Delta \mathrm{M} 15$ $\left.\operatorname{Tn} 10\left(\operatorname{Tet}^{\mathrm{R}}\right)\right\}$; Stratagene] was used as host for transformation of different plasmids. pBluescript was purchased from Stratagene, and pUCK4 $\left(\operatorname{Kan}^{\mathrm{R}} \mathrm{Amp}^{\mathrm{R}}\right)$ from Pharmacia. All strains were grown in Luria Broth at $37^{\circ} \mathrm{C}$ for plasmid manipulation. $X$. campestris growth media were either complete Luria Broth, containing fructose $(0.2 \%)$ when required, or synthetic MM1 medium supplemented with $0.2 \%$ of the appropriate carbon source (Roy et al., 1988). X. campestris was grown at $30^{\circ} \mathrm{C}$. Ampicillin and kanamycin were used when required at the respective final concentrations of $100 \mu \mathrm{g} \mathrm{ml}^{-1}$ and $50 \mu \mathrm{g} \mathrm{ml} \mathrm{m}^{-1}$.

Recombinant DNA techniques. Isolation of plasmid DNA, restriction endonuclease digestion, ligation, agarose electrophoresis and Southern experiments were performed as described in Sambrook et al. (1989). X. campestris was transformed by electroporation as previously reported (De Crécy-Lagard et al., 1990). X. campestris chromosomal DNA was prepared following Silhavy et al. (1984). Standard methods for DNA sequencing using dideoxynucleotides (Sanger et al., 1977) and singlestranded DNA from M13 phage (Messing \& Vieira, 1982) were employed. DNA sequencing was conducted using the T7 sequencing kit from Pharmacia. Universal primers were first used and subsequently primers were synthesized according to the sequence obtained in previous sequencing reactions. The synthetic oligonucleotides were furnished by the Service de Chimie organique, Institut Pasteur.

Construction of mutant $X$. campestris strains XC1509 and XC1510. A SmaI site situated 842 bp downstream from the putative start codon of the $f r u B$ gene was used for the inactivation of the gene by insertional mutagenesis. A $1.2 \mathrm{~kb}$ Bam HI-HincII fragment containing an internal portion of the fruB gene was cloned in the corresponding sites of $\mathrm{pBSK}^{+}$, yielding plasmid pDIA4838 (Fig. 1b). The kananamycin resistance gene of pUCK4 is entirely contained in a $1.3 \mathrm{~kb}$ HincII fragment. This fragment was cloned into the unique $S \mathrm{mal}$ site of pDIA4838, yielding pDIA4840. $X$. campestris was then electrotransformed by pDIA4840. $\mathrm{Kan}^{\mathrm{R}}$ transformants were selected and screened for sensitivity to ampicillin indicating that the vector had been lost and gene replacement had occurred corresponding to double crossovers. Previous experiments had shown that such events occur at high frequency in $X$. campestris (De Crécy-Lagard et al., 1990). Nineteen $\mathrm{Kan}^{\mathrm{R}}$ clones were obtained, of which $12(63 \%)$ were Amp's . Correct gene replacement at $f r u B$ was verified by Southern hybridization experiments. Chromosomal DNA isolated from strain XC1509, one of the pDIA4840 $\mathrm{Kan}^{\mathrm{R}} \mathrm{Amp} \mathrm{s}^{\mathrm{s}}$ transformants, was digested with BamHI and HincII and Southern hybridized with a $3 \mathrm{~kb}$ probe covering the $f r u B-f r u K$ region. The hybridization profile showed that the Bam HI-HincII fragment was $1.3 \mathrm{~kb}$ longer in the mutant than in the wild-type strain, indicating the correct insertion of the $\mathrm{Kan}^{\mathrm{R}}$ gene (data not shown). In similar attempts to obtain a $X$. campestris fruK mutant, the insertion by a single crossing-over event of a $\mathrm{pBSK}^{+}$derivative led to the construction of strain XC1510. As shown in Fig. 1(c), XC1510 contains an intact copy of the fruK gene and a copy in which a $\mathrm{Kan}^{\mathrm{R}}$ gene has been inserted upstream from the fru $A$ gene.

Computer analyses. Sequence analysis was performed with various programs included in the Genetics Computer Group package (1991).

Uptake and phosphorylation of $\left[{ }^{14} \mathrm{C}\right]$ fructose. Uptake of $\left[{ }^{14} \mathrm{C}\right]$ fructose by intact $X$. campestris cells and $\left[{ }^{14} \mathrm{C}\right]$ fructose phosphorylation in toluene-treated $X$. campestris cells were monitored as described previously (De Crécy-Lagard et al., 1991b), PEP being the phosphate donor at a final concentration of $5 \mathrm{mM}$. The final concentration of $\left[{ }^{14} \mathrm{C}\right]$ fructose was $50 \mu \mathrm{M}$ and its specific activity was $0.29 \mathrm{mCi} \mathrm{mmol}^{-1}\left(10.7 \mathrm{MBq} \mathrm{mmol}^{-1}\right)$. Uptake and phosphorylation measurements were performed at least three times each. The conditions of the PTS activity test were not optimized to measure PTS specific activities but to measure the presence or absence of a PEP-dependent phosphorylation activity. The results are therefore presented as the percentage of labelled fructose converted to phosphorylated $\left[{ }^{14} \mathrm{C}\right]$ fructose in the presence of PEP at $30^{\circ} \mathrm{C}$.

Preparation of cell-free extracts and spectrophotometric enzyme assays. Crude extracts of $X$. campestris cultures were prepared, and 1-PFK monitored, as previously described (De Crécy-Lagard et al., 1991a). Specific activity was defined as $\mu \mathrm{mol}$ substrate utilized $\mathrm{min}^{-1}(\mathrm{mg} \text { protein })^{-1}$.

\section{RESULTS AND DISCUSSION}

\section{Identification of a fruB gene upstream from the fruK gene in $X$. campestris}

We previously reported the cloning of a $18 \mathrm{~kb} E c o \mathrm{RI}$ fragment of $X$. campestris chromosomal DNA containing the two adjacent $f r u K$ and $f r u A$ genes encoding the 1-PFK and the domains IIB $^{\prime} \mathrm{BC}^{\mathrm{Fru}}$ of the fructose PTS respectively (De Crécy-Lagard et al., 1991a, b) (Fig. 1a). This organization was similar to that observed for the $E$. coli, S. typhimurium and R. capsulatus fructose operons. In these organisms, genes coding for the fructose PTS proteins, DTP or MTP, were adjacent to fruK (Prior \& Kornberg, 1988; Geerse et al., 1989; Orchard \& Kornberg, 1990; Reizer et al., 1994b; Wu et al., 1990, 1991).

The sequence of a 2623 bp DNA fragment located upstream from the fruK gene was therefore determined on both strands following the sequencing strategy outlined in Fig. 1(b). The nucleotide sequence is shown in Fig. 2. A possible coding sequence was identified on one strand, following the rules described by Sheperd (1981), from position 102 to position 2615, starting with a putative TTG codon at position 102-104. This start codon is preceded by a potential ribosome-binding site, GGAG, located $7 \mathrm{bp}$ upstream from the TTG initiation codon. The end of this coding sequence overlaps the initiation codon of the fruK gene, suggesting translational coupling. 
(a)

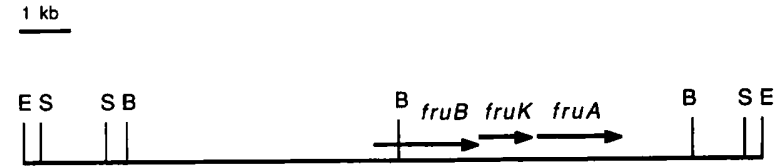

(b)

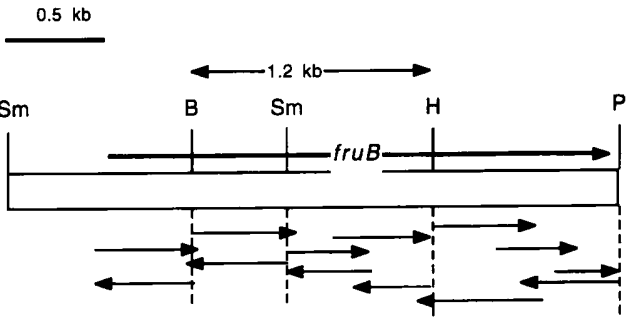

(c)

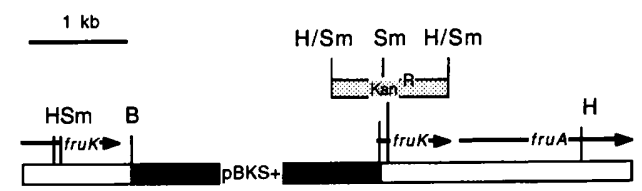

Fig. 1. (a) Restriction map of an $18 \mathrm{~kb}$ EcoRl fragment containing the fruB, fruK and fruA genes. The upper arrows represent the direction of transcription of the three genes. (b) Map of a $3.1 \mathrm{~kb}$ Smal-Pstl fragment upstream from the fruK gene. The $1.2 \mathrm{~kb}$ BamHI-Hincll fragment was ligated into the corresponding sites of the Bluescript vector $\mathrm{pBSK}^{+}$, yielding pDIA4838. The sequencing strategy of the $2.6 \mathrm{~kb}$ fragment upstream from the fruK gene is shown underneath. The arrows indicate sequencing direction of the clones used to obtain the nucleotide sequence of this DNA fragment. The location of the gene identified is shown by the upper arrow. (c) Map of the fruK-fruA region in mutant strain $X(1510$, showing the insertion of the $\mathrm{pBSK}^{+}$vector (dark shading) between a wildtype fruK gene and a fruK gene disrupted by $a K^{R}{ }^{R}$ gene (light shading). Restriction sites: E, EcoRI; S, Sall; B, BamHI; Sm, Smal; H, Hincll; P, Pstl.

Preceding the initiation codon, potential -10 and -35 regions were identified according to the $E$. coli standard promoter sequences. The two potential promoter sequences are separated by a $16 \mathrm{bp}$ palindrome that could act as a regulator site. Since in $X$. campestris fructose PTS activity is induced by fructose (De Crécy-Lagard et al., 1991b), regulation of the expression of the fru genes through this site is probable. It is interesting that the sequence of this palindrome differs from that of the $12 \mathrm{bp}$ palindrome which was shown to serve as the FruR binding site in the fru operon of S. typhimurium and E. coli (Ramseier et al., 1993). FruR is a pleiotropic transcriptional regulatory protein which negatively controls the expression of the $f r u$ operon in enteric bacteria (for a review see Postma et al., 1993). At the beginning of the sequenced fragment a short ORF of 40 nucleotides was identified following the rules described by Sheperd (1981), suggesting the presence of a coding sequence upstream from the first one.

The deduced amino acid sequence of the first coding sequence is shown in Fig. 2. A striking similarity (46\% identical residues) was found between the sequence of this 837 amino acid protein and the sequence of the $R$. capsulatus MTP protein encoded by the fruB gene (Wu et al., 1990). These results indicated that in X. campestris, like in $R$. capsulatus, a gene encoding an MTP is located upstream from the fruK gene.

\section{Comparison of the $X$. campestris MTP domains to known PTS enzymes}

Amino acid sequence comparisons indicate that the $X$. campestris MTP consists of three moieties (Fig. 3). The Nterminal moiety (residues 1-148) is homologous to the

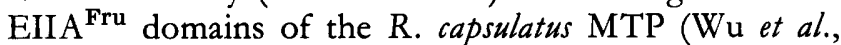
1990) and of the DTP proteins of E. coli (Reizer et al., 1994b) and S. typhimurium (Geerse et al., 1989). The central moiety (residues 161-251) is homologous to the HPr-like domains of the R. capsulatus MTP and of the DTP proteins of enteric bacteria. The $\mathrm{C}$-terminal domain (residues 274-837) is homologous to the Enzyme I domain of the $R$. capsulatus MTP and to the Enzyme I of E. coli and S. typhimurium (Saffen et al., 1987; De Reuse \& Danchin, 1988; LiCalsi et al., 1991).

The PTS Enzymes II have been classified into four major groups (Lengeler et al., 1990; Postma et al., 1993). As shown in Fig. 4, the EIIA ${ }^{\text {Fru }}$ domain of the $X$. campestris MTP clearly belongs to the EIIA ${ }^{\text {Mtl }}$ subclass. The homology found between the $\mathrm{N}$-terminal sequences of the E. coli EIIA ${ }^{\text {Mtl }}$ and the $X$. campestris MTP confirms the choice of the fruB starting codon. Nine members of this EIIA subclass have now been sequenced, and sequence comparisons can therefore provide evidence concerning potentially important structural and catalytic residues. We did not include the sequences of the recently discovered EII $^{\text {FrvA }}$ and EIIA ${ }^{\text {Ani }}$ domains (Reizer et al., 1994a; Saier \& Reizer, 1994) as it is not known if these proteins have a role in sugar transport in $E$. coli. The main conserved motif of the EIIA ${ }^{\text {Mtl }}$, A-PH, is found around $\mathrm{His}^{69}$ (referring to residue numbers of the protein alignment presented in Fig. 4), which has been shown to be phosphorylated in the E. coli enzyme (Van Weeghel et al., 1991). The role of the other conserved residues (Fig. 4) may become clear once the three-dimensional structure of the E. coli EIIA $^{\text {Mtl }}$ domain is resolved (Kroon et al., 1993). EIIA $^{\text {Fru }}$ domains from four organisms have now been sequenced. Only four residues are conserved in all EIIA $^{\text {Fru }}$ domains and absent in the EIIA ${ }^{\text {Mtl }}$ domains $\left(\mathrm{Gln}^{29}, \mathrm{Arg}^{75}, \mathrm{Gly}^{99}\right.$ and $\left.\mathrm{Ser}^{114}\right)$ whereas two residues are conserved in all EIIA ${ }^{\mathrm{Mtl}}$ domains and are absent in the EIIA $^{\text {Fru }}$ domains (Ala ${ }^{47}$ and Asp $/ \mathrm{Glu}^{99}$ ). These residues could be involved in specific interactions with the EIIBC $^{\text {Fru }}$ and EIIBC ${ }^{\text {Mtl }}$ domains respectively.

A number of $\mathrm{HPr}$ proteins have now been sequenced and it is interesting to note that the three-dimensional structural data and mutagenesis studies have confirmed the role of the residues that are highly conserved amongst these sequences. Four possible catalytic residues are conserved in all the compared sequences including the MTP sequence of X. campestris: $\mathrm{His}^{175}, \mathrm{Arg}^{177}, \mathrm{Ser}^{206}$ and 
T R S S T

AACCCGAAGCACTACAGGGTTTITGTGCACCGCACATTGACCIGGACCGTGGGAACGTTC $-35$

CCACIATACTTCCCAGCCGTTCCCCACCCCCGGAGCCCGCCTTGTCCTCTCCGTCGATTG

$\begin{array}{llllllllllllllllllll}P & V & T & P & D & L & V & R & L & R & A & T & A & R & D & K & D & D & A & I\end{array}$ CCCCCGTCACCCCCGACCTGGTGCGCCTGCGCGCCACTGCCCGCGACAAGGACGACGCCA

A Q A A Q L L V A A A G C V A TTGCCCAGGCCGCCCAGCTGCTGGTGGCAGCCGGATGCGTGGCGCCGGGCTACGACGCCA

$\begin{array}{llllllllllllllllllll}M & R & R & R & E & G & L & A & N & T & F & L & G & H & G & L & A & I & P & H\end{array}$ GCATGCGGCGGCGCGAAGGCCTGGCGAATACTTTCCTGGGCCACGGCCTGGCGATTCCGC

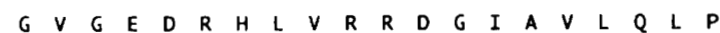
ACGGCGTGGGCGAAGACCGGCACCTGGTGCGCCGCGACGGCATCGCGGTGCTGCAGCTGC

$\begin{array}{llllllllllllllllllll}E & G & V & E & W & N & P & G & Q & T & T & R & L & V & V & G & I & A & A & Q\end{array}$ CCGAGGGCGTGGAATGGAACCCCGGCCAGACCACCCGCCTGGTGGTGGGCATCGCCGCCC

$\begin{array}{llllllllllllllllllll}S & D & T & H & I & T & L & V & R & R & L & T & R & L & I & Q & D & P & A & Q\end{array}$ AGTCCGACACCCACATCACCCTCGTGCGCCGGCTGACCCGCCTGATCCAGGATCCGGCCC

$\begin{array}{llllllllllllllllllll}L & E & A & L & F & T & T & D & D & P & A & V & I & V & A & A & L & T & G & D\end{array}$ AGCTGGAAGCGCTGTTCACCACCGACGACCCGGCCGTGATCGTGGCCGCGCTGACCGGCG

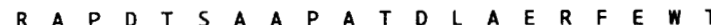
ACCGCGCACCCGACACCAGCGCCGCCCCGGCCACCGACCTGGCCGAACGGTTCGAATGGA

$\begin{array}{llllllllllllllllllll}I & A & Y & P & S & G & L & H & A & R & P & A & T & R & W & A & E & T & A & R\end{array}$ CCATCGCCTACCCCAGCGGCETGCACGCGCGCCCGGCCACTCGCTGGGCGGAGACCGCGC

$\begin{array}{llllllllllllllllllll}G & F & S & A & R & A & Q & V & R & A & G & 0 & Q & A & A & D & A & K & S & L\end{array}$ GCGGCTTTTCGGCCCGCGCCCAGGTCCGCGCCGGTGACCAGGCCGCCGATGCCAAGAGCC

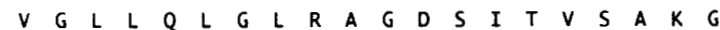
IGGTCGGCCTGCTGCAACTGGGCCTGCGCGCCGGCGACAGCATTACGGTCTCAGCGAAAG

$\begin{array}{llllllllllllllllllll}S & D & A & P & A & L & L & K & R & L & R & A & V & M & D & S & L & T & A & Q\end{array}$ GCAGCGATGCCCCCGCCCTGCTCAAGCGCCTGCGCGCGGTGATGGACAGCCTGACCGCGC

$\begin{array}{llllllllllllllllllll}E & K & A & D & A & E & R & A & A & Q & R & R & A & A & P & V & I & G & W & T\end{array}$ AGGAAAAGGCCGATGCCGAACGLGCCGCGCAACGCCGCGCCGCACCGGTCATCGGCTGGA

$\begin{array}{llllllllllllllllllll}P & P & Q & A & Q & P & A & I & V & G & I & G & A & S & P & G & V & A & I & G\end{array}$ CCECGCCGCAGGCGCAGCCGGCCATCGTCGGCATCGGCGCCAGCCCGGGCGTGGCAATCG SmaI

$\begin{array}{llllllllllllllllllllllllll}I & V & H & R & L & R & A & A & Q & T & E & V & A & 0 & Q & P & I & G & L & G\end{array}$ GCATCGTGCACCGCCTGCGTGCCGCGCAGACCGAGGTGGCCGACCAGCCGATCGGCCTGG

$\begin{array}{llllllllllllllllllll}D & G & G & V & L & L & H & D & A & L & T & R & T & R & 0 & O & L & A & A & I\end{array}$ GCGACGGCGGCGTGCTGCTGCATGACGCCCTCACCCGCACCCGCCAGCAGCTGGCCGCCA

$\begin{array}{llllllllllllllllllll}Q & D & D & T & Q & R & R & L & G & A & S & D & A & A & I & F & K & A & Q & A\end{array}$ TCCAGGACGACACCCAGCGCCGCCTGGGCGCCTCGGACGCGGCGATCTTCAAGGCCCAGG

$\begin{array}{llllllllllllllllllll}E & L & L & N & D & T & D & L & I & T & R & T & C & Q & L & M & V & E & G & H\end{array}$ CCGAGCTGCTCAACGACACCGACCTGATCACCCGCACCTGCCAGCTGATGGTCGAAGGCC

G V A W S W H Q A V E Q I A S G L A A L ACGGTGTGGCGTGGTCGTGGCACCAGGCGGTGGAACAGATCGCCTCCGGCCTCGCGGCGC

$\begin{array}{llllllllllllllllllll}G & N & P & V & L & A & G & R & A & A & D & L & R & D & V & G & R & R & V & L\end{array}$ TGGGCAACCCGGTGCTGGCCGGCCGCGCCGCTGACCTGCGCGACGTGGGCCGCCGTGTGC

$\begin{array}{llllllllllllllllllll}A & Q & L & D & A & A & A & A & G & A & G & L & T & D & L & P & E & Q & P & C\end{array}$ TGGCCCAACTCGACGCGGCAGCGGCCGGCGCCGGCCTCACCGACCTGCCCGAGCAGCCCT

$\begin{array}{llllllllllllllllllll}I & L & L & A & G & D & L & S & P & S & D & T & A & N & L & D & T & D & C & V\end{array}$ GCATCCTGCTCGCCGGCGACCTGTCGCCGTCGGACACCGCCAACCTCGACACCGATTGCG

$\begin{array}{llllllllllllllllllll}L & G & L & A & T & A & O & G & G & P & T & S & H & T & A & I & L & S & R & T\end{array}$ TGCTTGGCCTGGCCACCGCCCAGGGTGGGCCGACCTCGCACACCGCGATCCTGTCGCGCA

$\begin{array}{llllllllllllllllllll}L & G & L & P & A & L & V & A & A & G & G & Q & L & L & D & I & E & D & G & V\end{array}$ CGCTCGGCCTGCCGGCGCTGGTCGCGGCTGGCGGCCAGTTGCTGGATATCGAAGACGGCG

$\begin{array}{llllllllllllllllllll}T & A & I & I & D & G & S & S & G & R & L & Y & I & N & P & S & E & Q & D & L\end{array}$ TCACCGCCATCATCGACGGCAGCAGCGGGCGGCTCTACATCAACCCGTCAGAACAGGATC

D A A A R TGGACGCCGCCCGCACGCATATCGCCGAGCAGCAGGCCATCCGCGAGCGCGAAGCCGCCC

$\begin{array}{llllllllllllllllllll}R & A & L & P & A & E & T & T & D & G & H & H & I & D & I & G & A & N & V & N\end{array}$ AGCGCGCCCTGCCCGCCGAAACCACCGACGGCCACCACATCGACATCGGCGCCAACGTCA

$\begin{array}{llllllllllllllllllll}L & P & E & Q & V & A & M & A & L & T & Q & G & A & N & V & G & L & M & R & T\end{array}$ ACCTGCCCGAGCAGGTGGCCATGGCCTTGACCCAGGGCGCCAACGTGGGCCTGATGCGCA

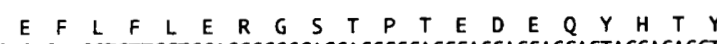
CAGAGTTCCTGTTCCTGGAGCGCGGCAGCACGCCCACCGAGGACGAGCAGTACCACACCT

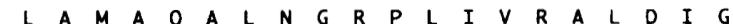
ACCTGGCAATGGCACAGGCCCTGAATGGCCGCCCGCTGATCGTGCGTGCGCTGGACATCG

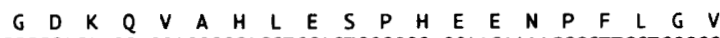
GCGGCGACAAGCAGGTGGCGCACCTGGAGTCGCCGCACGAAGAAAACCCGTTCCTGGGCG

$\begin{array}{llllllllllllllllllll}R & G & A & R & L & S & S & R & R & P & D & L & L & E & P & Q & S & R & A & L\end{array}$ TGCGTGGCGCGCGCCTGTCGTCGCGCCGCCCCGACCTGCTCGAGCCACAGTCGCGGGCGC

$\begin{array}{llllllllllllllllllll}Y & R & A & A & K & D & G & A & R & L & S & I & M & F & P & M & I & T & S & V\end{array}$ TGTATCGCGCGGCCAAGGACGGCGCACGGCTGTCGATCATGTTCCCGATGATCACCTCGG

$\begin{array}{llllllllllllllllllll}P & E & L & I & S & L & R & E & I & C & A & A & I & R & A & E & L & H & A & P\end{array}$ TGCCGGAGCTGATCAGCCTGCGCGAGATCTGCGCAGCCATCCGCGCCGAACTGCACGCAC

E L P I G I M I CGGAGCTGCCGATCGGCATCATGATCGAAGTGCCCGCCGCCGCCGCCCAGGCCGATGTGC

$\begin{array}{llllllllllllllllllll}A & R & H & A & D & F & F & S & I & G & T & N & D & L & T & Q & Y & V & L & A\end{array}$ TGGCGCGCCATGCGGATTTCTTCTCGATCGGCACCAACGACCTCACCCAATACGTGCTGG

I $D$ R $Q$ N $N$ P $P$ E L A A E A S S S L H P A V L CAATCGACCGCCAGAACCCGGAACTGGCCGCCGAAGCCAGCAGCCTGCATCCGGCGGTGC

$\begin{array}{llllllllllllllllllll}R & M & I & R & S & T & I & D & G & A & R & K & H & D & R & W & V & G & V & C\end{array}$ TGCGCATGATCCGCAGCACGATTGACGGCGCGCGCAAGCACGACCGCTGGGTCGGGGTGT

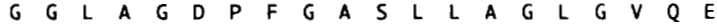
GCGGCGGTCTGGCCGGCGACCCGTTCGGCGCCAGCCTGCTGGCCGGGCTGGGCGTGCAGG

$\begin{array}{llllllllllllllllllll}L & S & M & T & P & N & D & I & P & A & V & K & A & R & L & R & G & R & A & L\end{array}$ AATTGTCGATGACGCCCAACGACATTCCGGCGGTCAAGGCGCGGCTGCGTGGCAGGGCGC

$\begin{array}{llllllllllllllllllll}S & A & L & Q & Q & L & A & E & Q & A & L & H & C & E & T & A & E & Q & V & R\end{array}$ TGAGCGCCTTGCAGCAGCTGGCCGAGCAGGCGCTGCACTGCGAGACCGCAGAGCAGGTGC

A L E A O R E G $Q$ G A *

GTGCGCTTGAAGCACAGCGCGAGGGCCAGGCATGAGCCTGCAG $M S$ L Q

Fig. 2. Nucleotide sequence of the $2623 \mathrm{bp}$ fragment located upstream of the fruK gene. The putative sequence corresponding to the -35 and -10 regions of a promoter and the SD region are underlined. The $16 \mathrm{bp}$ palindrome is indicated by arrows above the sequence. The linker regions in the coding sequence are underlined.

Asp $^{229}$ (numbers refer to the position in the $X$. campestris MTP sequence) (data not shown). $\mathrm{His}^{175}$, the phosphorylation site (Beyreuther et al., 1977), and Arg ${ }^{177}$ are part of the active site (Herzberg et al., 1992). $\mathrm{Ser}^{206}$ is phosphorylated in an ATP-dependent manner only in Gram-positive bacteria (Reizer et al., 1989). Mutating Asp ${ }^{229}$ significantly reduces PTS activity (Sharma et al., 1991) and as this residue is located on an outer flexible loop (Herzberg et al., 1992), it could be involved in interactions with the EIIA domains. The HPr domain of DTP can substitute for HPr in E. coli and S. typhimurium (Geerse et al., 1986; Waygood, 1980). No sequence specificity could be detected in the fructose HPr-like proteins since no residues conserved only in these proteins and not in the general HPr proteins could be identified. However, whereas in general HPr proteins are acidic in nature ( $\mathrm{pI} 4 \cdot 0-5 \cdot 6$ ) it is noteworthy that the $X$. campestris $\mathrm{HPr}$ domain has a very high isoelectric point (pI 10.6) like the $R$. capsulatus and $E$. coli fructose-inducible $\mathrm{HPr}$ domains ( $\mathrm{pI} 9 \cdot 9-10 \cdot 2$ ) and the Mycoplasma capricolum $\mathrm{HPr}$ (pI 9-18) (Zhu et al., 1993).

Eight Enzyme I proteins have been sequenced and a remarkable degree of conservation between enzymes of very diverse origins can be noticed. Local similarities of Enzyme I proteins with the pyruvate:orthophosphate dikinase (PPDK) of maize (Pocalyko et al., 1990) and the PEP synthase (PPS) of E. coli (Niersbach et al., 1992) 


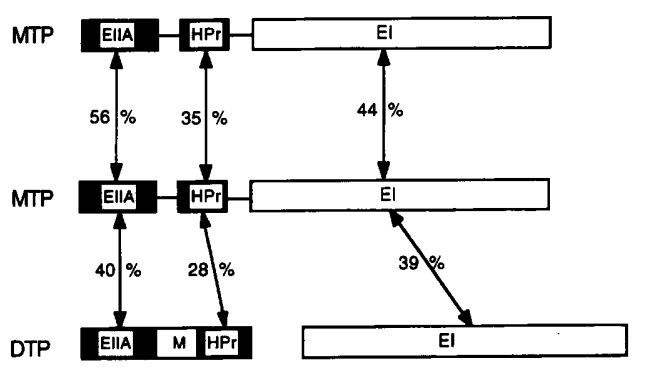

R. capsulatus
X. campestris
E. coli
S. typhimurium

Fig. 3. Comparison of the $X$. campestris MTP with the $R$. capsulatus MTP and with the DTP and El proteins of $E$. coli and $S$. typhimurium. The percentage of identical residues between the $X$. campestris protein and the corresponding domains from the three other bacteria are indicated. Abbreviations: EllA, EIIA ${ }^{\text {Fru}} ; M$, central domain of the DTP of enteric bacteria (Wu et al., 1990).

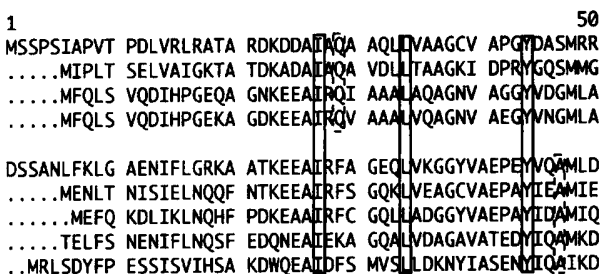

...

100 REGLANTF.. LGHGLPAPAG VGEORHLVRR DGIAVLQLPE GVEWN. . P,'G REAVANTF. . LGNGIPHPHG LPQDRDLIHD TAIAVVQLPA GVEWA. .PYG REQQTSTF. LGNGIPH PHG TTDTRDOVLK TGVQVFQFPQ GVTWG.. EEG REQQTSTF. . LGNGIPHPHG TTDTKDQVLK TGVQVFQFPE GVTWG. . D'G REKLTPTY. . LGESI. PHG TVEAKDRVLK TGVVFCQYPE GVRFGEEEP, RDQLLSAH.. MGNFIA PHAG TEEAKKLVKK SGICWVQVPE GWWFGTEEP RDKELSVY.. MGNFIL PHF TDDAKKDVLK SGITWQVVPD GWWFGTEDD REAVVSTF.. MGNGLAAPHG TDEAKSAVLQ SGLTLLQIPE GUWWG. . Do STINNGPYYI LAPGVAPEHA RPE. . CGALK TGMSLTLLEQ GVYFPGNGEP

101 QTTRLVVGI. AQQSTDTHTLL VRRLTRLIQD PAQLEALFTT DDPAVIVAALTGDR DTARLVVAI. AAKSOEL QV LSNLTDVLGD EAEAERLATT LDAAVIVARLT... OVAYVAIGI. ARSSOEL GL LROLTHVISD DSVAEQLKSA TTAEELRALLMGEK OVAYVAIGI. AASSSDP LLL LRQLTHVLSD DSVAEQLKSA TTAEELRALLMGEK

DIARLVIGI. AARNNGETOV ITSLTNALDD ESVIERLAHT TSVDEVLELLAGRK KIATVLFGI. AGVGEQtLQL VQQIALYCSD MDNVVQLADA LSKEEITENLAIA. QVATVLFGI. AEIGDELQI IQNISIFCAD VONVVKLADA OTEDEVVKLLSQVW . VAKVWVGI. AGKDGG LDL LSKIAITFSE EENVDRIVNT KSPEEIKAVFEEAD .. IKLLIGLS ARDADSHIGA IQALSELLCE EEILEQLLTA SSEKQLADIISRG

Fig. 4. Alignments of amino acid sequences of four sequenced ElIA ${ }^{\text {Fru }}$ domains and five sequenced EIIA ${ }^{\text {MtI }}$ domains of the bacterial PTS. Residues conserved in the nine proteins are boxed. Residues conserved only in the EIIA ${ }^{\mathrm{Fru}}$ or only in the EllA $^{\mathrm{Mtl}}$ class are boxed with dashed lines. Numbering above the aligned sequence corresponds to the residue position in the multiple alignment. Numbers to the upper left of the sequences shown indicate the first amino acid of the compared protein. Abbreviations and references of published sequences are as follows. For the EllA ${ }^{\text {Fru }}$ domains: $X$. C., X. campestris; $R$. C., $R$. capsulatus (Wu et al., 1990); S. t., S. typhimurium (Geerse et al., 1989); E. C., E. coli (Reizer et al., 1994b). For the EllA ${ }^{\mathrm{Mtl}}$ domains: E. C., E. coli (Lee \& Saier, 1983); E. f., Enterococcus faecalis (Fischer et al., 1991); S. C., Staphylococcus carnosus (Fischer et al., 1989); S. m., Streptococcus mutans (Honeyman \& Curtiss, 1992). E.c Cmt is the sequence of the cryptic mannitol permease identified by Sprenger (1993). permitted the identification of two conserved regions: one surrounding $\mathrm{His}^{\mathbf{4 6 0}}$ (referring to the $X$. campestris MTP sequence), which is the phosphorylated residue in Enzyme I (Meadow et al., 1990), and the second being the potential PEP-binding site (amino acids 692-730) (Wu et al., 1990; Gagnon et al., 1992; Reizer et al., 1993). These conserved motifs are also found in the X. campestris MTP sequence (data not shown).

Several authors have suggested that fusion and dissociation of protein domains must have occurred frequently during the evolution of PTS proteins (Wu et al., 1990; Postma et al., 1993). The PTS protein domains are often separated by general linkers, $Q$ linkers and Ala/Prorich hinges (Erni et al., 1987; Wu et al., 1990; Postma et al., 1993). We observed that the three $X$. campestris MTP moieties are separated by two linkers (Fig. 2). The nucleotide sequences of these linkers are GC-rich ( $80 \mathrm{~mol} \%$ ) compared to the surrounding sequenced region $(70 \mathrm{~mol} \%)$, and rich in $\mathrm{Ala}$, Pro and charged residues. The two linkers of the $X$. campestris MTP are not homologous and differ from the R. capsulatus MTP linkers. We propose that the absence of structural constraint in these regions explains the incorporation of a higher percentage of $\mathrm{G}$ and $\mathrm{C}$ residues in first and second codon positions in organisms of high GC content. The consequence is a high number of Ala and Pro residues which, by their flexibility, happen to be good linker region residues.

\section{Construction and characterization of an $X$. campestris fruB mutant}

The SmaI site situated $842 \mathrm{bp}$ downstream from the putative start codon of the $f r u B$ gene (Fig. 2) was used for the inactivation of the gene by insertional mutagenesis and the fruB:: $\mathrm{Kan}^{\mathrm{R}}$ strain XC1509 was constructed as described in Methods. Like the fru $A$ mutant (strain $\mathrm{XC1504)}$ isolated in previous studies (De Crécy-Lagard et al., 1991b), strain XC1509 grew normally on glucose but failed to grow on fructose, mannose, mannitol or sucrose (minimal medium agar plates supplemented with $0.2 \%$ of the carbon source). The absence of growth on fructose was not surprising but as mannose, sucrose and mannitol did not seem to be sugars taken up by the PTS in $X$. campestris, the inability of a fruA or fruB PTS mutant to utilize these carbon sources was unexpected. We previously proposed that this phenotype was due to the fact that these carbon sources were transformed into fructose after their uptake into the cell and that intracellular fructose is in $X$. campestris partly metabolized through the PTS (De Crécy-Lagard et al., 1991b). It has been confirmed recently that mannose is indeed transformed into fructose in X. campestris by an isomerase (Harding et al., 1993).

Uptake of $\left[{ }^{14} \mathrm{C}\right]$ fructose was monitored in the wild-type strain and in the fruB mutant strain. As shown in Fig. 5, the rate of $\left[{ }^{14} \mathrm{C}\right]$ fructose uptake was 20 times slower in the mutant strain XC1509. PEP-dependent phosphorylation of $\left[{ }^{14} \mathrm{C}\right]$ fructose in toluenized mutant cells was four times 


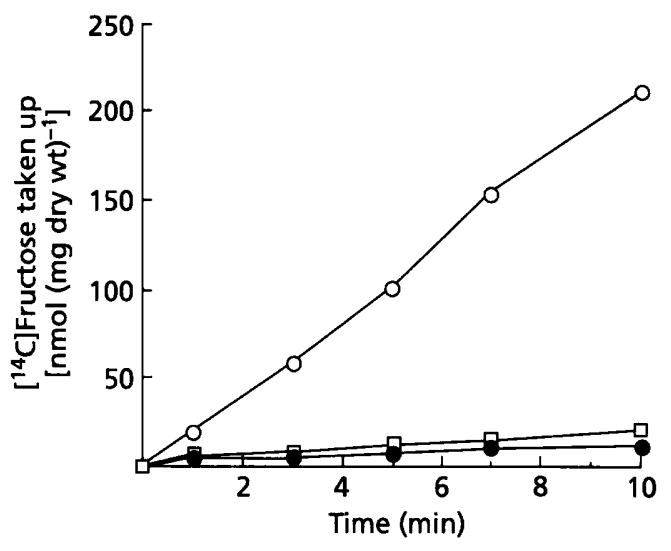

Fig. 5. Uptake of $\left[{ }^{14} \mathrm{C}\right]$ fructose by intact $X$. campestris cells. $O$, Wild-type; $\square, X C 1510 ; 0, X C 1509$. Uptake of $\left[{ }^{14} \mathrm{C}\right]$ fructose was monitored as described in Methods.

Table 1. $\left[{ }^{14} \mathrm{C}\right]$ Fructose phosphorylation in toluenetreated $X$. campestris cells

PEP-dependent phosphorylation was monitored as described in Methods, with assay times of 5 or $15 \mathrm{~min}$ at $30^{\circ} \mathrm{C}$. The PEP concentration was $5 \mathrm{mM}$.

\begin{tabular}{|c|c|c|c|c|}
\hline & \multicolumn{4}{|c|}{ Phosphorylated $\left[{ }^{14} \mathrm{C}\right]$ fructose $(\%)$} \\
\hline & \multicolumn{2}{|c|}{$5 \mathrm{~min}$} & \multicolumn{2}{|c|}{$15 \mathrm{~min}$} \\
\hline & -PEP & + PEP & -PEP & + PEP \\
\hline Wild-type & 3.7 & $32 \cdot 4$ & 6.7 & 44 \\
\hline $\mathrm{XC1504}($ fru $A)$ & $1 \cdot 5$ & 8 & $1 \cdot 8$ & 9 \\
\hline $\mathrm{XC1509}($ fruB $)$ & $1 \cdot 8$ & $11 \cdot 5$ & 3.9 & 10 \\
\hline XC1510 (FruK $\left.{ }^{-}\right)$ & 3 & 23 & $3 \cdot 4$ & $29 \cdot 4$ \\
\hline
\end{tabular}

less efficient than that in wild-type cells (Table 1). Since fruK is immediately adjacent to $f r u B$, the insertion of a $\mathrm{Kan}^{\mathbf{R}}$ gene in $f r u B$ was expected to exert a polar effect on fruK. 1-PFK activity was therefore measured in strain XC1509. No 1-PFK activity could be detected in XC1509 cells when an activity of $0.234 \mu \mathrm{mol} \mathrm{min}^{-1}(\mathrm{mg} \text { protein })^{-1}$ was found in the wild-type cells. The $\operatorname{Kan}^{\mathbf{R}}$ gene insertion in the fruB gene was thus polar on the downstream fruK gene. It is highly probable that the two genes are in the same transcriptional unit and subject to translational coupling, as seems to be the case for the equivalent genes in E. coli and R. capsulatus (Jones-Mortimer \& Kornberg, 1974; Wu et al., 1991). However, it seems unlikely that the pts phenotype of the $f r u B$ insertional mutant is due to a polar effect on the downstream fruK gene.

We also do not favour the hypothesis that the phenotype of the fruB insertional mutant is due to a polar effect on the distal fruA gene, for the following reasons. We have shown previously that an $X$. campestris fru $A$ null mutant could be complemented in trans by a DNA fragment containing the $3^{\prime}$-end of the fruK gene, the $120 \mathrm{bp}$ intergenic region and the fru $A$ gene cloned in a broad- host-range plasmid (De Crécy-Lagard et al., 1991b). This strongly suggested that the $f r u A$ gene was transcribed from its own promoter located in the intergenic region separating fruK from fru $A$ and not from the fruB promoter region. In addition, unlike the situation in the other sequenced fru operons, where the $f r u K$ and $f r u A$ genes are only separated by approximately $20 \mathrm{bp}$ (Prior \& Kornberg, 1988; Wu et al., 1991), the fruK and fru $A$ genes of $X$. campestris are separated by $120 \mathrm{bp}$. Moreover a potential terminator sequence and consensus promoter sequences were identified between these two genes (De Crécy-Lagard et al., 1991a), again suggesting that fru $A$ is not part of the fruB-fruK transcriptional unit. This hypothesis was confirmed by the phenotype of strain XC1510 (Fig. 1c). This strain, described in Methods, has an unexpected FruK $^{-}$phenotype which could be due to a transdominant negative phenotype of the truncated copy of the fruK gene as 1-PFK enzymes are most likely multimeric (Von Hugo \& Gottschalk, 1974). XC1510 does not grow on fructose, fructose uptake is impaired (Fig. 5) and no 1-PFK activity can be detected in cell extracts. However, PTS activity in toluenized cells of $\mathrm{X} 1510$ is comparable to that in cells of the wild-type (Table 1), showing that an insertion in fruK has no polar effect on the fruA gene. These arguments make it highly probable that the $\mathrm{Pts}^{-}$phenotype of the fruB::Kan ${ }^{\mathrm{R}}$ mutant is due to the inactivation of the $f r u B$ gene itself and confirms the role of the MTP in the X. campestris fructose PTS.

\section{ACKNOWLEDGEMENTS}

We wish to thank $H$. De Reuse for critical reading of the manuscript and O. Bouvet for performing the 1-PFK activity assays. Support for this work was provided by grant UA1129 from the Centre National de la Recherche Scientifique and grant ST20478 from the EEC. V. de Crécy-Lagard was supported by a Rhone-Poulenc fellowship.

\section{REFERENCES}

Beyreuther, K., Raufuss, H., Schrecker, O. \& Hengstenberg, W. (1977). The phosphoenolpyruvate-dependent phosphotransferase system of Staphylococcus aureus 1. Amino acid sequence of the phosphocarrier protein HPr. Eur J Biochem 75, 275-286.

De Crécy-Lagard, V., Glaser, P., Lejeune, P., Sismeiro, O., Barber, C. E., Daniels, M. J. \& Danchin, A. (1990). A Xanthomonas campestris pv. campestris protein similar to catabolite activation factor is involved in regulation of phytopathogenicity. $J$ Bacteriol 172, $5877-5883$.

De Crécy-Lagard, V., Bouvet, O. M. M., Lejeune, P. \& Danchin, A. (1991a). Fructose catabolism in Xanthomonas campestris pv. campestris. Sequence of the PTS operon, characterization of the fructose-specific enzymes. $J$ Biol Chem 266, 18154-18161.

De Crécy-Lagard, V., Lejeune, P., Bouvet, O. M. M. \& Danchin, A. (1991b). Identification of two fructose transport and phosphorylation pathways in Xanthomonas campestris pv. campestris. Mol \& Gen Genet 227, 465-472.

De Reuse, H. \& Danchin, A. (1988). The $p t s H, p t s I$, and $c r r$ genes of the Escherichia coli phosphoenolpyruvate-dependent phosphotransferase system: a complex operon with several modes of transcription. J Bacteriol 170, 3827-3837.

Erni, B., Zanolari, B. \& Kocher, H. P. (1987). The mannose permease 
of Escherichia coli consists of three different proteins. Amino acid sequence and function in sugar transport, sugar phosphorylation and penetration of phage $\lambda$ DNA. J Biol Chem 262, 5238-5247.

Fischer, R., Eisermann, R., Reiche, B. \& Hengstenberg, W. (1989). Cloning, sequencing and overexpression of the mannitol specific enzyme-III-encoding gene of Staphylococcus carnosus. Gene 82, 249-257.

Fischer, R., Pogge van Strandmann, R. \& Hengstenberg, W. (1991). Mannitol-specific phosphoenolpyruvate-dependent phosphotransferase system of Enterococcus faecalis: molecular cloning and nucleotide sequences of the Enzyme III ${ }^{\mathrm{Mtl}}$ gene and the mannitol-1-phosphate dehydrogenase gene, expression in Eschericbia coli and comparison of the gene products with similar enzymes. J Bacteriol 173, 3709-3715.

Gagnon, G., Vadeboncoeur, C., Lesveque, R. C. \& Frenette, M. (1992). Cloning, sequencing and expression in Escherichia coli of the $p t s I$ gene encoding enzyme I of the phosphoenolpyruvate:sugar phosphotransferase transport system from Streptococcus salivarius. Gene 121, 71-78.

Geerse, R. H., Ruig, C. R., Schuitema, A. R. J. \& Postma, P. W. (1986). Relationship between pseudo-HPr and the PEP:fructose phosphotransferase system in Salmonella typhimurium and Escherichia coli. Mol \& Gen Genet 203, 435-444.

Geerse, R. H., Izzo, F. \& Postma, P. W. (1989). The PEP: fructose phosphotransferase system in Salmonella typhimurium: FPr combines Enzyme III ${ }^{\mathrm{Fru}}$ and pseudo-HPr activities. Mol \& Gen Genet 216, 517-525.

Genetics Computer Group (1991). Program Manual for the GCG Package, Version 7, April 1991. Genetics Computer Group, 575 Science Drive, Madison, WI 53711, USA.

Harding, N., Raffo, S., Raimondi, A., Cleary, J. \& lelpi, L. (1993). Identification, genetic and biochemical analysis of genes involved in synthesis of sugar nucleotide precursors of xanthan gum. $J \mathrm{Gen}$ Microbiol 139, 447-457.

Herzberg, O., Reddy, P., Sutrina, S., Saier, M. H., Reizer, J. \& Kadapia, G. (1992). Structure of the histidine-containing phosphocarrier protein $\mathrm{HPr}$ from Bacillus subtilis at $2 \cdot 0-\AA$ resolution. Proc Natl Acad Sci US A 89, 2499-2503.

Honeyman, A. L. \& Curtiss, R. (1992). Isolation, characterization, and nucleotide sequence of the Streptococcus mutans mannitolphosphate dehydrogenase gene and the mannitol-specific factor III gene of the phosphoenolpyruvate phosphotransferase system. Infect Immun 60, 3369-3375.

Jeanes, A., Pittsley, J. E. \& Senti, F. R. (1961). Polysaccharide B1459: a new hydrocolloid polyelectrolyte produced from glucose by bacterial fermentation. J Appl Polym Sci 5, 519-526.

Jones-Mortimer, M. C. \& Kornberg, H. L. (1974). Genetical analysis of fructose utilization by Escherichia coli. Proc R Soc Lond Ser B 187, 121-131.

Kroon, G. J. A., Grötzinger, J., Dijkstra, K., Scheek, R. M. \& Robillard, G. T. (1993). Backbone assignments and secondary structure of the Escherichia coli enzyme-II mannitol A domain determined by heteronuclear three dimensional NMR spectroscopy. Protein Sci 2, 1331-1341.

Lee, C. A. \& Saier, M. H., Jr (1983). Mannitol-specific Enzyme II of the bacterial phosphotransferase system. III. Nucleotide sequence of the permease gene. $J$ Biol Chem 258, 10761-10767.

Lengeler, J. W., Titgemeyer, F., Vogler, A. P. \& W6hrl (1990). Structure and homologies of carbohydrate:phosphotransferase system (PTS) proteins. Phil Trans R Soc Lond Ser B 326, 489-504.

LiCalsi, C., Crocenzi, T. S., Freire, E. \& Roseman, S. (1991). Sugar transport by the bacterial phosphotransferase system. Structural and thermodynamic domains of Enzyme I of Salmonella typhimurium. $J$ Biol Chem 266, 19519-19527.

Meadow, N. D., Fox, D. K. \& Roseman, S. (1990). The bacterial phosphoenolpyruvate:glycose phosphotransferase system. Annu Rev Biochem 59, 497-542.

Messing, J. \& Vieira, J. (1982). A new pair of M13 vectors for selecting either DNA strand of double-digest restriction fragments. Gene 19, 269-276.

Niersbach, M., Kreuzaler, F., Geerse, R. H., Postma, P. W. \& Hirsch, H. J. (1992). Cloning and nucleotide sequence of the Escherichia coli K-12 pps $A$ gene, encoding PEP synthase. Mol \& Gen Genet 231, 332-336.

Orchard, L. M. D. \& Kornberg, H. L. (1990). Sequence similarities between the gene specifying 1-phosphofructokinase ( $\mathrm{fruK}$ ), genes specifying other kinases in Escberichia coli $\mathrm{K} 12$ and lacC of Stapbylococcus aureus. Proc R Soc Lond Ser B 242, 87-90.

Pocalyko, D. J., Carroll, L. J., Martin, B. M., Babbitt, P. C. \& Dunaway-Mariano, D. (1990). Analysis of sequence homologies in plant and bacterial pyruvate phosphate dikinase, Enzyme I of the phosphoenolpyruvate: sugar phosphotransferase system and other PEP-utilizing enzymes. Identification of potential catalytic and regulatory motifs. Biochemistry 29, 10757-10765.

Postma, P. W., Lengeler, J. W. \& Jacobson, G. R. (1993). Phosphoenolpyruvate: carbohydrate phosphotransferase system of bacteria. Microbiol Rev 57, 543-594.

Prior, T. I. \& Kornberg, H. L. (1988). Nucleotide sequence of fru $A$, the gene specifying enzyme $\mathrm{II}^{\mathrm{Fru}}$ of the phosphoenolpyruvatedependent sugar phosphotransferase system in Escherichia coli K12. $J$ Gen Microbiol 134, 2757-2768.

Ramseier, T. M., Nègre, D., Cortay, J.-C., Scarabel, M., Cozzone, A. J. \& Saier, M. H., Jr (1993). In vitro binding of the pleiotropic transcriptional regulatory protein, FruR, to the fru, $p p s$, ace, pts and icd operons of Escherichia coli and Salmonella typhimurium. J Mol Biol 234, 28-44.

Reizer, J., Sutrina, S. L., Saier, M. H., Stewart, G. C., Peterkofsky, A. \& Reddy, P. (1989). Mechanistic and physiological consequences of $\mathrm{HPr}$ (ser) phosphorylation on the activities of the phosphoenolpyruvate: sugar phosphotransferase system in Gram-positive bacteria: studies with site-specific mutants of $\mathrm{HPr}$. EMBO $J \mathbf{8}$, 2111-2120.

Reizer, J., Hoischen, C., Reizer, A., Pham, T. N. \& Saier, M. H., Jr (1993). Sequence analyses and evolutionary relationships among the energy-coupling proteins Enzyme I and HPr of the bacterial phosphoenolpyruvate: sugar phosphotransferase system. Protein $S_{c i}$ 2, 506-521.

Reizer, J., Michotey, V., Reizer, A. \& Saier, M. H., Jr (1994a). Novel phosphotransferase system genes revealed by bacterial genome analysis: unique, putative fructose- and glucoside-specific systems. Protein Sci 3, 440-450.

Reizer, J., Reizer, A., Kornberg, H. L. \& Saier, M. H., Jr (1994b). Sequence of the fruB gene of Escherichia coli encoding the diphosphoryl transfer protein (DTP) of the phosphoenolpyruvate:sugar phosphotransferase system. FEMS Microbiol Lett 118, 159-162.

Roy, A., Glaser, P. \& Danchin, A. (1988). Aspects of regulation of adenylate cyclase synthesis in Escherichia coli K12. J Gen Microbiol 134, 359-367.

Saffen, D. W., Presper, K. A., Presper, T. L., Doering, T. L. \& Roseman, S. (1987). Sugar transport by the phosphotransferase system. Molecular cloning and structural analysis of the Escherichia coli ptsH, ptsI and crr genes. J Biol Cbem 262, 16241-16253.

Saier, M. H. \& Reizer, J. (1992). Proposed uniform nomenclature 
for proteins and protein domains of the phosphoenolpyruvate:sugar phosphotransferase system. $J$ Bacteriol 174, 1433-1438.

Saier, M. H. \& Reizer, J. (1994). The bacterial phosphotransferase system: new frontiers 30 years later. Mol Microbiol 13, 755-764.

Saier, M. H., Yamada, M., Erni, B., Suda, K., Lengeler, J., Ebner, R., Argos, P., Rak, B., Schnetz, K., Lee, C. A., Stewart, G. C., Breidt, F., Waygood, E. B., Peri, K. G. \& Doolittle, R. F. (1988). Sugar permeases of the bacterial phosphoenolpyruvate-dependent phosphotransferase system: sequence comparisons. FASEB J 2, 199-208.

Sambrook, J., Fritsch, E. F. \& Maniatis, T. (1989). Molecular Cloning: a Laboratory Manual, 2nd edn. Cold Spring Harbor, NY: Cold Spring Harbor Laboratory.

Sanger, F., Nicklen, S. \& Coulson, A. R. (1977). DNA sequencing with chain terminating inhibitors. Proc Natl Acad Sci USA 74, 5463-5467.

Sharma, S., Georges, F., Delbaere, L. T. J., Lee, J. S., Klevit, R. E. \& Waygood, E. B. (1991). Epitope mapping by mutagenesis distinguishes between the two tertiary structures of the histidinecontaining protein HPr. Proc Natl Acad Sci USA 88, 4877-4881.

Sheperd, J. C. W. (1981). Method to determine the reading frame of a protein from the purine/pyrimidine genome sequence and its evolutionary justification. Proc Natl Acad Sci US A 78, 1596-1600.

Silhavy, T. J., Berman, M. L. \& Enquist, L. W. (editors) (1984). Experiments with Gene Fusions. Cold Spring Harbor, NY: Cold Spring Harbor Laboratory.

Sprenger, G. A. (1993). Two open reading frames adjacent to the Escherichia coli $\mathrm{K}-12$ transketolase $(t k t)$ gene show high similarity to the mannitol phosphotransferase system enzymes from Escherichia coli and various Gram-positive bacteria. Biocbim Biophys Acta 1158, 103-106.

Sutherland, I. W. \& Ellwood, D. C. (1979). Microbial exopolysaccharides - industrial polymers of current and future potential. Symp Soc Gen Microbiol 29, 107-150.
Van Weeghel, R. P., Meyer, G. H., Keck, W. \& Robillard, G. T. (1991). Phosphoenolpyruvate-dependent mannitol phosphotransferase system of Escherichia coli: overexpression, purification and characterization of the enzymatically active C-terminal domain of Enzyme II ${ }^{\mathrm{Mtl}}$ equivalent to Enzyme III ${ }^{\mathrm{Mtl}}$. Biochemistry 30, 1774-1779.

Von Hugo, H. \& Gottschalk, G. (1974). Purification and properties of 1-phosphofructokinase from Clostridium pasteurianum. Eur $J$ Biocbem 48, 455463.

Waygood, E. B. (1980). Resolution of the phosphoenolpyruvate: fructose phosphotransferase system of Escherichia coli into two components: enzyme $\mathrm{II}^{\mathrm{Fru}}$ and fructose-induced HPr-like protein (FPr). Can J Biochem 58, 1144-1146.

Wu, L.-F. \& Saier, M. H., Jr (1990). Nucleotide sequence of the fruA gene, encoding the fructose permease of the Rhodobacter capsulatus phosphotransferase system, and analyses of the deduced protein sequence. $J$ Bacteriol 172, 7167-7178.

Wu, L.-F., Tomich, J. M. \& Saier, M. H., Jr (1990). Structure and evolution of a multidomain multiphosphoryl transfer protein. Nucleotide sequence of the $f r u B(H I)$ gene in Rbodobacter capsulatus and comparison with homologous genes from other organisms. $J$ Mol Biol 213, 687-703.

Wu, L.-F., Reizer, A., Reizer, J., Cai, B., Tomich, J. M. \& Saier, M. H., Jr (1991). Nucleotide sequence of the Rbodobacter capsulatus fruK gene, which encodes fructose-1-phosphate kinase: evidence for a kinase superfamily including both phosphofructokinases of Escherichia coli. J Bacteriol 173, 3117-3127.

Zhu, P.-P., Reizer, J., Reizer, A. \& Peterkovsky, A. (1993). Unique monocistronic operon ( $p t s H)$ in Mycoplasma capricolum encoding the phosphocarrier protein, $\mathrm{HPr}$, of the phosphoenolpyruvate: sugar phosphotransferase system. J Biol Chem 268, 26531-26540.

Received 17 March 1995; revised 5 May 1995; accepted 19 May 1995. 